\title{
Processo de importação em uma empresa automobilística
}

Josmária Lima Ribeiro Oliveira Doutoranda em Ciência da Informação pela Universidade Federal de Minas Gerais UFMG Professora da Pontifícia Universidade Católica de Minas Gerais - PUC Minas Rua São Manoel, 171. Floresta. Belo Horizonte/MG. CEP: 31015-390 E-mail: josmaria@pucminas.br

Antônio Artur de Souza Ph.D em Ciências Administrativas/Lancaster/UK Professor da Universidade Federal de Minas Gerais - UFMG Avenida Antonio Carlos, 6627, sala 2030. Campus Pampulha. Belo Horizonte/MG E-mail: artur@face.ufmg.br

Karla Lorena Bessa Ribeiro Graduação em andamento em Administração pela Pontifícia Universidade Católica de Minas Gerais - PUC Minas R. Necésio Machado da Silva, 149. Barreiro de Baixo. Belo Horizonte/MG. CEP: 30.640655 E-mail: pesquisaimportacao@yahoo.com.br

\section{RESUMO}

O volume nacional de importação é representativo, porém não tem sido abordado profundamente no Brasil, pois dá-se preferência aos incentivos à exportação. No setor automobilístico a atividade de importação é constante e, portanto, requer um processo ágil e preciso. Nesse contexto, este artigo apresenta os resultados de uma pesquisa baseada em estudo de caso desenvolvido em uma indústria automobilística no Brasil. $O$ artigo contempla três objetivos: (1) descrever o processo de importação; (2) identificar os fatores que influenciam o processo de compra de produtos importados; e (3) descrever o sistema de estimação de custos utilizado. A coleta de dados foi realizada por meio de entrevistas não-estruturadas, questionários semi-estruturados e análise documental das planilhas utilizados nas atividades de estimação de custos. Foi possível descrever o processo de importação da indústria, identificar os custos logísticos e o sistema de estimação de custos utilizado. Este artigo é uma contribuição para a compreensão da atividade de importação e estimação de custos na atividade de importação, e revela a complexidade da ação de compra organizacional no mercado internacional.

Palavras chave: Importação. Estimação de Custos. Indústria Automobilística. 


\section{ABSTRACT}

National volume of international purchases is representative, however it has not been boarded deeply in Brazil, therefore preference to the incentives to the exportation is given. Automobile sector has international purchases constantly, and therefore, it requires fast and fair process. This paper presents the results of a research based on case study of developed in Brazil automobile industry. There are three objectives for this research: (1) to describe the importation process, (2) to identify factors that influence the process of international purchase of products and (3) to describe the system of estimation costs. Data collection was carried of not-structuralized interviews, halfstructuralized questionnaires and documentary analysis of the spread sheets used in the activities of costs estimation. It was possible to describe international purchases process of automobile industry, to identify costs logistics and cost estimation systems used. This paper contributed to understanding the process of international purchases and costs estimation in the activity of importation, and discloses the complexity of the action in the international market.

Keywords: International purchases. Costs Estimation. Automobilistic Industry.

\section{INTRODUÇÃO}

O Brasil apresenta um expressivo volume de importação e é um dos países que mais importa no mundo. No entanto, o processo de importação é complexo e apresenta vários riscos. No setor automobilístico a atividade de importação é constante e, portanto, requer um processo ágil e preciso. O crescimento das importações no setor automobilístico ocorreu a partir do ano de 1992/1993, apresentando o seu maior volume de importação em 1997; US\$ 5.105 milhões.

A estimação de custos no processo de importação é complexa, pois a comercialização internacional envolve fatores externos não controlados pela empresa. À medida que o nível de atenção dedicado às compras e suprimentos aumenta, o trabalho tende a tornar-se mais estratégico na busca da redução do custo total (Baily et al., 2000). Para definir o valor a ser despendido para a aquisição de um produto importado, deve-se considerar que o custo total de aquisição não se refere apenas ao preço do produto ou serviço, pois existem diversos custos que fazem parte do processo de compra da mercadoria. 
Neste contexto, os objetivos desta investigação consistem em: (1) descrever o processo de importação; (2) identificar fatores que influenciam o processo de compra de produtos importados; e (3) descrever o sistema de estimação de custos utilizado. O artigo está dividido em nove seções: (1) introdução; (2) a elucidação teórica da atividade de importação, que apresenta ao leitor uma construção desenvolvida a partir da pesquisa bibliográfica e permite a identificação do processo; (3) o estado da arte referente aos fatores que influenciam a estimação de custos; (4) a análise de pesquisas e definições referentes à análise de sistemas de informação; (5) a descrição da metodologia, que demonstra como foi desenvolvido o trabalho e como foram realizadas as análises dos dados; (6) o desenvolvimento do estudo de caso, que contempla informações específicas sobre a indústria automobilística por meio da descrição da atividade de importação; (7) a análise dos fatores que influenciam a estimação de custos para a importação; (8) a apresentação do processo, que envolve o pedido de importação, contemplando os custos logísticos e o sistema utilizado; e (9) a apresentação das conclusões obtidas a partir do desenvolvimento da pesquisa.

\section{PROCESSO DE IMPORTAÇÃO}

Para realizar a estimação de custos de importação, o tomador de decisão precisa compreender características específicas da comercialização. É necessário ter claro conhecimento do produto a ser adquirido, com as especificações básicas necessárias e a variação de quantidade permitida. A partir destas informações tem início a definição dos parâmetros para a negociação. Para Kotabe e Helsen (2000), o modelo de compra do importador consiste em três estágios que apresentam diretrizes para a decisão. $O$ primeiro estágio consiste na necessidade de reconhecimento e formulação do problema e envolve os fatores que motivam a ação. O segundo estágio corresponde à procura, ou seja, a identificação das características do país, do fornecedor e de outras informações relevantes para a tomada de decisão. O terceiro estágio contempla a escolha, que é procedida a partir das alternativas remanescentes 
avaliadas para a tomada de decisão. A importação é realizada como um processo de compra organizacional.

Segundo Kotler (2000), o processo de compra consiste em oito estágios, denominados de fases da compra. O Quadro 1, adaptado de Oliveira e Souza (2004), apresenta os principais componentes de custos analisados para a estimação de custos na importação pelo tomador de decisão. Para a análise destes componentes considerou-se Oliveira et al. (2006a) e Oliveira et al. (2006b).

\begin{tabular}{|c|c|}
\hline & ITEN \\
\hline INCOTERM & EXW, FCA, FAZ, FOB, CFR, CIF, CPT, CIP, DAF, DES, DEQ, DDU, \\
\hline \multirow{4}{*}{ Transporte } & Frete (pré-transporte, transporte internacional, pós-transporte) \\
\hline & $\begin{array}{l}\text { Modalidades (modal, segmentado, sucessivo, combinado, } \\
\text { intermodal, multimodal) }\end{array}$ \\
\hline & Embalagem (primária, secundária) \\
\hline & Seguro \\
\hline \multirow{7}{*}{ Taxas de importação } & AFRMM (Adicional ao Frete para Renovação da Marinha Mercante) \\
\hline & ATA (Adicional de Tarifas Aeroportuárias) \\
\hline & Taxa de armazenagem \\
\hline & Taxa de capatazia \\
\hline & DI - Declaração de importação \\
\hline & Despesas bancárias \\
\hline & Conhecimento de Embarque \\
\hline Despacho aduaneiro & Honorário de despachante aduaneiro \\
\hline Custo do pedido & Programação, desenvolvimento, controle e avaliação. \\
\hline
\end{tabular}

Quadro 1: Síntese dos componentes de custos na importação Fonte: Adaptado de Oliveira e Souza (2004)

No Brasil, a tributação sobre o produto nacional é maior que o produto importado, pois o PIS e o Cofins (e até dez/2007 a CPMF) incidem várias vezes sobre o produto nacional, dependendo do tamanho da cadeia produtiva. Diante dessa questão, observa-se que em determinadas situações o produto pode ficar mais barato, se vir de outro país, principalmente, se nesse país não há incidência de impostos em cascata sobre suas cadeias produtivas. Oliveira e Souza (2004) apresentam o fato gerador e a base de cálculo de cada imposto incidente sobre a atividade de importação. 


\section{FATORES NO PROCESSO DE IMPORTAÇÃO}

Considera-se que a ação de realizar compras, hoje, assume uma posição estratégica nas empresas, pois a maior parte das atividades dos colaboradores focados em compras se concentra no estabelecimento e no desenvolvimento de relacionamentos apropriados com os fornecedores, o que permite melhoria de desempenho. Alguns meios comumente usados para mensurar o desempenho de compras são: a qualidade, a quantidade, o tempo de entrega, o preço e os custos operacionais. Portanto, acredita-se que a área de compras é uma função gerencial básica (Baily et al., 2000).

Souza (1995) apresenta um modelo para a estimação de custos de uma empresa de produção por encomenda, o qual é aplicável ao estudo da estimação de custos para a atividade de importação. $O$ autor considera que o processo de estimação de custos requer a análise de um conjunto de fatores internos e externos. O modelo definido por Souza (1995) foi desenvolvido a partir de uma pesquisa empírica em empresas Inglesas, no período de 1991 a 1995. Diversos trabalhos, como os de Souza et al., (1999a); Souza et al., (1999b); Souza e Kingsman (1999), vêm sendo publicados desde então, apresentando este modelo como adequado para a realidade brasileira.

A partir da teoria desenvolvida por Souza (1999b), foi possível identificar que existem fatores a serem considerados no processo de estimação de custos. Os fatores internos entendidos como componentes do custo de determinados produtos cujo cálculo leva em consideração fatores internos da empresa, considerados nesse estudo como determinantes na tomada de decisão. Já os fatores externos afetam direta e indiretamente a estimação de custos e formação de preços, e por isso se constituem em tarefa muito importante para as empresas. Tais fatores são determinados pelas mudanças no ambiente em que a empresa está operando.

\subsection{Risco de perdas}

Williamsom (1985) define risco como distúrbios exógenos não controláveis que 
afetam as transações. Consiste na existência da possibilidade de atitudes oportunistas. As perdas na atividade de importação podem ser referentes às condições de transferência e qualidade do produto. A qualidade do produto é comprometida pela forma de transferência do produto ou serviço prestado. O tipo de transporte pode incorrer em perdas devido ao tempo em que o produto ficou embalado, os movimentos gerados pela locomoção do produto e a variação de temperatura a que o produto foi submetido.

\subsection{Situação financeira da empresa}

Para uma empresa importar determinada mercadoria deve se observar os recursos financeiros disponíveis para a execução dessa atividade, pois, em geral, a comercialização externa é realizada mediante apenas um pagamento, exigindo que a empresa apresente disponibilidade de recursos para tal. Para Ross et al., (1995), à medida que a empresa possui fluxo de caixa suficiente, ela não se torna inadimplente em relação às suas obrigações financeiras.

\subsection{Capacidade de estocagem do produto}

A análise da capacidade produtiva se refere à especificação do lote, ou seja, da quantidade a ser adquirida em cada comercialização. Sobre a capacidade de alocar o produto importado, Ribeiro (2002) afirma que a empresa necessita avaliar este fator na tomada de decisão para evitar o risco de importar e não ter capacidade para processar os produtos. A partir da abordagem feita por Slack et al., (1996), é possível obter uma posição sobre como deve ser considerado o volume de ressuprimento do estoque da empresa.

\subsection{Confiabilidade no fornecedor e no produto importado}

A análise sobre a confiabilidade do produto ou serviço prestado considera o posicionamento da marca e da empresa em relação às suas concorrentes. A confiança existe quando o cliente sente segurança em relação à fidedignidade e à integridade de 
um parceiro. Quando este fator é considerado na tomada de decisão, resulta em um comprometimento da empresa em estar cumprindo estas expectativas com responsabilidade (Ribeiro; Pereira, 2002; Almeida et al., 2002).

Para Carvalho (2002), existem três abordagens sobre o significado do termo confiança, bem como sobre os processos por meio dos quais ela é construída e mantida: a) confiança calculada (o homem é um agente racional que analisa os custos e benefícios antes de entrar em uma relação); b) confiança baseada em normas ou valores (a lealdade e obrigação estão em primeiro plano); e c) confiança cognitiva (expectativas mantidas sobre a ordem social em geral e as interações específicas com os outros).

\subsection{Benefícios e restrições governamentais}

Segundo Kotler (2000), ao comercializar com outros países a empresa deve observar as normas e as leis comerciais vigentes nestes países, a situação da moeda, e a possibilidade de ocorrerem distúrbios políticos. Por exemplo, a tributação causa um grande impacto no Brasil, além da situação do câmbio. No entanto outras medidas merecem a consideração do importador. Estas medidas envolvem, por exemplo, as negociações coletivas realizadas pelo governo com as empresas envolvidas no setor alfandegário, pois podem ser geradas revoltas que impliquem na possibilidade dos portos alfandegários entrarem em greve, assim como órgãos reguladores do governo.

Para Barbosa Filho e Freire (1999), o Custo Brasil resulta do crescente descompasso entre as condições ofertadas às empresas em outros países e as ofertadas pelo governo brasileiro às empresas instaladas no país para a consecução dos seus objetivos. O custo Brasil advém da desigualdade na incidência tributária; da falta de investimentos em infra-estrutura como energia, transporte e telecomunicação, que são os meios pelos quais são concretizados os negócios das empresas, comprometendo a continuidade das atividades produtivas. Os tributos incidentes sobre a importação no Brasil podem provocar situações em que o produto pode ficar mais barato vindo de outro país, principalmente, se nesse país não houve a incidência de 
impostos em cascata sobre suas cadeias produtivas.

A variação cambial é um outro ponto a ser considerado, pois no Brasil esta variação está presente e gera ao importador a dificuldade de realizar pagamentos futuros diante da possibilidade de elevação do valor da moeda estrangeira. Portanto, este é mais um fator que direciona as empresas a atuarem com pagamento à vista.

\subsection{Tempo de entrega}

A forma de transporte pode variar segundo as condições geográficas, causando interferência: o clima, a temperatura, o relevo, as reformas das vias, as guerras ou guerrilhas e os acordos entre países. No transporte internacional as alternativas de rotas são restritas face ao limitado número de portos e pontos alfandegários para deixar ou entrar no país (Ballou, 2001). O tomador de decisão deve observar a sua necessidade e disponibilidade de tempo e recursos para tomar a decisão de como deverá ser feito o transporte do produto ou equipamento (Lopez, 2000).

\subsection{Alta concorrência entre os fornecedores}

A identificação das empresas que fornecem o produto ou serviço é feita a partir de pesquisa de mercado. Para Baily et al., (2000), a busca de fornecedores pode ser realizada informalmente quando compradores conversam com vendedores, visitam feiras comerciais, lêem periódicos e investigam o mercado antes de realizar pedidos. Sendo assim, a pesquisa identifica o conjunto de fontes reais e potenciais que constituem um mercado fornecedor. Para tanto, recebe análise a capacidade, as tendências e as perspectivas de longo prazo do mercado. Uma outra forma de divulgação dos produtos é feita por meio de revistas técnicas que são direcionadas para setores específicos.

A escolha entre os fornecedores concorrentes leva em consideração o preço praticado, alicerçado pela credibilidade que o fornecedor tem no mercado. Os atributos de um bom fornecedor, ainda segundo os autores são: entrega pontual, qualidade consistente, bom preço, antecedentes estáveis, bom serviço, responsivo às 
necessidades do cliente, cumprimento do prometido, fornecimento de apoio técnico, e constante emissão de informação sobre o andamento do pedido. Para um mesmo produto existem muitos fornecedores, e estes fornecedores têm preços competitivos, ou seja, estes concorrem entre si de forma acirrada, pois buscam evitar a possibilidade de existirem fornecedores alternativos.

\subsection{Avanços tecnológicos do produto para o comprador}

É preciso considerar constantemente o impacto da tecnologia para avaliar se novas tecnologias podem alterar o valor do produto. Pois, com o surgimento de uma nova tecnologia, um produto pode ter seu preço reduzido, uma vez que deixou de ser tão inovador e interessante para os clientes finais. O desenvolvimento de tecnologia relacionada ao produto e a suas características apóia a toda cadeia de valor, portanto, o avanço tecnológico tem implicações competitivas (Porter, 1989).

\subsection{Comunicação/negociação com o fornecedor}

Uma outra perspectiva de análise para este fator consiste na facilidade de comunicação/negociação com o fornecedor. O comércio com o uso da internet é um grande atrativo para as empresas que comercializam internacionalmente. $O$ cenário B2B permite que vários custos de comercialização sejam reduzidos e que todas as informações técnicas sejam repassadas sem ruídos na comunicação. Para Baily et al., (2000), com a tecnologia o comprador pode ter mais tempo para negociação, desenvolvimento de fornecedores e redução de custos.

\subsection{Interesse de clientes da empresa no produto}

Este fator diz respeito ao interesse da empresa importadora em adquirir um produto ou serviço. Este fator pode ser relevante a ponto de direcionar a empresa a uma compra que desconsidere o preço para analisar as características próprias de um produto e de suas atribuições. Tal fator emprega a análise da cadeia de valor, pois em termos competitivos, valor é o montante que os clientes estão dispostos a pagar por 
aquilo que uma empresa lhes fornece (Porter, 1989). Entre as atividades de valor de apoio encontra-se a aquisição que é a função de compra de insumos empregados na cadeia de valor da empresa.

\subsection{Negócios potenciais com o fornecedor}

Souza (1999b) considera que o preço do produto ou serviço prestado pode ser reduzido mediante a freqüência de consumo da empresa importadora. Este procedimento é utilizado por empresas que estimam o valor de vida do cliente e exercem políticas de fidelização que acumulam benefícios à empresa, permitindo a política de descontos progressivos (Rust et al., 2001). A repetição da negociação com o mesmo fornecedor permite que a empresa importadora esteja mais confiante em relação à aquisição do produto ou serviço prestado e que futuras negociações possam ser realizadas com o mesmo fornecedor.

\subsection{Negócios potenciais com futuros clientes}

Para a tomada de decisão sobre a importação de produtos ou serviços deve ser analisada a frequência, ou seja, o grau de recorrência das transações. Para Santos (2002), a frequência associa-se à possibilidade da internalização de uma determinada operação produtiva (também denominada de integração vertical) dado um alto índice de recorrência observado. Este tipo de relacionamento contratual fundamentado na frequência de ocorrência de um produto, implica na estimação de custos do produto ou serviço.

O valor do cliente para a exportadora, segundo Rust et al., (2001, p.64), baseiase em três fatores: "Valor do Valor, a avaliação objetiva, pelo cliente, das ofertas da empresa; Valor da Marca, a visão subjetiva, pelo cliente, da empresa e suas ofertas; e Valor de Retenção, a visão, pelo cliente, da força da relação entre ele e a empresa". 


\section{SISTEMAS DE INFORMAÇÃO PARA A ESTIMAÇÃO DE CUSTOS}

De acordo com Stair (1998, p. 312), a avaliação de Sistemas de Informação visa "determinar se os objetivos alcançados pelo sistema atual estão satisfazendo ou não as metas da empresa". Por meio dessa avaliação podem ser identificados possíveis problemas ou oportunidades ainda não relevadas. De acordo com Zwass (1992), devese analisar qual informação é necessária, bem como a qualidade dessa informação; pois quando se implementa um SI espera-se que este forneça informações com a qualidade esperada. Zwass (1992) considera que os atributos fundamentais da informação de qualidade são: conveniência, exatidão, precisão, ser completa, relevância e forma apropriada.

Zanoteli (2001) realizou um estudo de casos múltiplos sobre avaliação de SIs por meio da percepção de valor dos usuários. Para tanto, o autor fez uso de outro método além do método da percepção de valor dos usuários (avaliando os atributos das informações e dos sistemas): a estrutura WCA de Alter (1996). Esse modelo de avaliação de SI foi também utilizado por Cardoso (2001) na avaliação de um sistema SAP R/3. Alter (1996) propõe um método denominado Análise Centrada no Trabalho (WCA - Work-Centered Analysis). O método é baseado no princípio de que o administrador pode e deve analisar os Sls focalizando o trabalho que está sendo realizado. $O$ trabalho, neste contexto, é considerado como a aplicação de recursos que podem ser utilizados por clientes internos e externos: pessoas, equipamentos, tempo, e dinheiro para gerar saídas.

Um SI pode também ser avaliado levando em consideração a relação custo/benefício. De acordo com Zwass (1992), a análise custo/benefício procura estabelecer se os benefícios gerados por um SI superam os custos necessários para sua implementação. Segundo Stair (1998, p. 326), "a análise custo/benefício é uma técnica que lista todos os custos e benefícios" da implantação de um SI.

Freitas; Ballaz e Moscarola (1994) desenvolveram um modelo para avaliação de SI baseado em dois pilares: facilidade de uso (ligada ao sistema e à interação usuário- 
sistema) e utilidade (ligada ao usuário ou tomador de decisão, suas funções, atividades e processos nos quais está envolvido). Com base nesse modelo e nos atributos da informação apresentados por Zwass (1992), Cohen e Souza (2001) avaliaram um SI utilizando 15 atributos (ou variáveis), divididos em três grupos: a) quanto ao sistema aspecto funcional, interface, disponibilidade e acesso; b) quanto às informações conteúdo, apresentação, quantidade, digitação, oportunidade, exatidão, precisão, completude, concisão e relevância; e c) quanto à opinião geral sobre o sistema avaliação geral do sistema.

Maçada et al., (2000) utilizaram um método desenvolvido por Torkzadeh e Doll (1999) para avaliar a satisfação do usuário de um protótipo de SAD (Sistema de Apoio à Decisão). Este método está baseado em quatro constructos $\mathrm{x}$ produtividade do trabalho, inovação no trabalho, satisfação do usuário e controle gerencial, que estão representados por um total de 12 questões e que têm como finalidade avaliar o impacto da Tecnologia da Informação no trabalho do usuário final. Gobbo (2002) também utilizou esse método para avaliar a satisfação do usuário de um SI. Além de avaliar a satisfação do usuário, avaliou a utilidade do sistema, baseando-se em três itens: eficácia do software do sistema (método dos fatores críticos de sucesso), impacto na estrutura funcional da empresa (análise dos processos) e análise dos indicadores de desempenho.

Como se pode perceber, diversos são os métodos para avaliar os Sls. É importante que a escolha do método esteja baseada naquilo que se pretende avaliar e que a avaliação não esteja centrada apenas no retorno financeiro do investimento em $\mathrm{SI}$, mas também nos benefícios intangíveis que esse $\mathrm{SI}$ pode proporcionar e nas informações que ele pode disponibilizar.

\section{METODOLOGIA}

Nessa pesquisa utilizou-se o método exploratório e descritivo, tendo como procedimento técnico o estudo de caso. Para Martins e Lintz (2000), "o estudo de caso 
possibilita a penetração na realidade social, não conseguida plenamente pela análise e pela avaliação quantitativa". No entanto, segundo Yin (2001), não são permitidas generalizações. Para Kilpatrick (1988) um estudo de caso não constitui por si só uma metodologia de investigação bem definida, mas essencialmente um design de investigação.

Trata-se de um tipo de pesquisa que tem sempre um forte cunho descritivo. $O$ investigador não pretende intervir sobre a situação, mas dá-la a conhecer tal como ela Ihe surge. Para isso, apoia-se numa descrição factual, literal, sistemática e, tanto quanto possível, completa do seu objeto de estudo. No entanto, um estudo de caso não tem de ser meramente descritivo; pode ter, igualmente, um profundo alcance analítico; pode interrogar a situação; confrontar a situação com outras situações já conhecidas e com as teorias existentes; ajudar a gerar novas teorias e novas questões para futura investigação (Merrian, 1988; Yin, 2001).

O ambiente de análise foi o departamento de compras de uma empresa automobilística, no setor de desenvolvimento de fornecedores. A empresa é atuante no mercado nacional desde 1976, apresenta uma linha diversificada de produtos e emprega na unidade entrevistada 17.000 trabalhadores, produzindo 1.800 carros por dia. A empresa investe na expectativa de crescimento do mercado interno e investe também na ampliação das exportações. Os principais mercados da empresa são a América Latina, Europa e países da África e Oriente Médio.

A pesquisa caracterizou-se como exploratória, pois trata de um assunto revelador que confirma as definições de Malhotra (2001) e Cooper e Schindler (2003). Para Malhotra (2001, p.106), a pesquisa exploratória pode ser usada para formular um problema ou defini-lo com maior precisão entre outros fatores. Os dados foram coletados em entrevistas e procurou-se garantir a validade e confiança dos resultados desta pesquisa com a "atenção cuidadosa à conceitualização do estudo e à forma pela qual os dados são coletados, analisados, e interpretados, e à forma na qual as descobertas são apresentadas" (Merrian, 1988, p. 200).

As entrevistas foram semi-estruturadas, que para Triviños (1987, p.138), é um 
dos "instrumentos mais decisivos para estudar os processos e produtos nos quais está interessado o investigador qualitativo". Além desta abordagem, foi utilizado um questionário estruturado ao final da coleta de dados para validar a interpretação dos fatos apresentados. Outra forma de coleta de dados consistiu na análise documental que envolveu a análise do instrumento utilizado para a estimação de custos dos produtos importados.

Os dados coletados foram submetidos a diversas técnicas de análise, incluindo: análise de conteúdo, técnica de triangulação e modelagem. A análise de conteúdo foi utilizada com a finalidade de explicitar e sistematizar o conteúdo da mensagem, por meio da análise confirmatória de dados. Para Bardin (1977), a análise de conteúdo é como um conjunto de técnicas de análise das comunicações, e Babbie (1999, p.71) expressa que "análise de conteúdo tem a vantagem de fornecer um exame sistemático de materiais em geral avaliados de forma mais impressionística". A triangulação foi fundamental para que os dados coletados de diferentes fontes fossem analisados de maneira integrada. A modelagem permitiu recriar o contexto no qual os dados foram gerados.

\section{PROCESSO DE IMPORTAÇÃO}

O setor de importação da indústria automobilística é coordenado por um mestre em Engenharia de Produção e graduado em Engenharia Mecânica, que ocupa a função há 3 anos. O gestor iniciou suas atividades na empresa na área comercial, e em seguida atuou no departamento de compras. Atualmente, neste mesmo departamento, atua no desenvolvimento de fornecedores, na importação e exportação, e também no mercado interno.

A empresa pratica a produção contínua. Os produtos importados consistem em partes e peças; raramente são importadas máquinas e efetuadas compras de materiais indiretos à produção. Os principais motivos que induzem a empresa a atuar com importações consistem nos incentivos fiscais à importação e na competitividade dos 
preços externos. Em alguns casos, ocorre a importação em virtude da ausência de fornecedores locais, ou pela confiabilidade no fornecedor externo. Contudo, os principais motivos são a competitividade internacional que resulta em preços competitivos e acordos internacionais com a matriz do grupo.

Em geral, os produtos importados não são perecíveis e não necessitam do envio de especificações, pois todas as peças são identificadas apenas pelo código prédeterminado com os fornecedores credenciados pela empresa. Sobre o licenciamento, considera-se que em alguns poucos casos faz-se necessária a verificação pela alfândega como, por exemplo, na importação de Air Bag, por ser considerado explosivo. A empresa apresenta três níveis de fornecedores e todos devem ser credenciados pela indústria. Para tanto, precisam apresentar certificações de qualidade e se submeter a avaliação de peritos da indústria automobilística, que acompanham inclusive a saúde financeira das empresas. Apesar de demonstrar esta proximidade de controle, os fornecedores não realizam contratos de exclusividade anual, mas necessitam apresentar no início do ano o valor a ser praticado durante todo o período anual.

Os produtos importados são enviados de um país europeu, e as análises do grupo referente aos custos dos produtos são realizadas em Euro. Considera-se, contudo, que os produtos importados nem sempre são produzidos na Europa e não apresentam a circulação da carga no Continente, pois grande parte dos produtos importados é fabricada na China e na Índia. Os Continentes que enviam cargas para o Brasil são a América do Norte, América do Sul, Europa, Ásia e África.

As modalidades de transporte mais utilizadas pela empresa são o marítimorodoviário, o aéreo-rodoviário e o rodoviário-rodoviário. Cerca de $70 \%$ de todos os produtos importados são transportados pelo marítimo-rodoviário. Os custos de transporte do porto à fábrica são praticamente nulos, pois esta realiza exportações constantes, e como o volume de importação é inferior, o retorno do caminhão que levou a carga de exportação ao porto traz a carga de importação. O transporte rodoviáriorodoviário origina-se na Argentina, que há 3 anos tinha uma fábrica de carros do grupo no país. Após o fechamento desta fábrica, os fornecedores acentuaram a 
comercialização de peças para o Brasil. A embalagem das peças é unitária, sendo acondicionadas em paletes e contêineres de 20/40 pés. Cada fornecedor necessita ter a embalagem de madeira definida pela matriz, para que a carga seja acondicionada de forma adequada no contêiner sem variações na quantidade.

A programação da fábrica é realizada anualmente. Para os fornecedores locais utiliza-se o sequenciamento com a entrega diária e na hora exata da entrada da peça na produção. O tempo de entrega das peças internacionais varia entre 30 e 35 dias, dependendo dos trâmites nos portos e do local de origem. As cargas vindas da Turquia têm o prazo médio de 35 dias e as vindas da Itália podem chegar em até 28 dias; no entanto, as cargas que têm como origem a China necessitam de 40 dias.

Algumas peças necessitam de consolidação por não terem ocupado todo contêiner. Nestes casos, as cargas são encaminhadas para a Turquia ou para a Itália, em portos que apresentam agentes do grupo que procedem a consolidação. A margem de segurança utilizada pela empresa é de 7 dias. O porto utilizado pela empresa é o do Rio de Janeiro, e após o desembarque no porto a carga é direcionada por meio rodoviário.

A modalidade de compra utilizada na importação é CIF. Algumas raras vezes é utilizada a modalidade FOB. Em relação ao prazo de pagamento, considera-se que a importação permite a efetuação deste em 90 dias pela ação Intercompany, ao contrário do mercado interno, que apresenta um prazo de pagamento reduzido. A empresa possui benefício fiscal, de acordo com as políticas do setor automobilístico. O estimador de custos utiliza a incidência de 10,8\% para a estimação de custos, como taxa de importação.

\section{ANÁLISE DE FATORES PARA ESTIMAÇÃO DE CUSTOS NA IMPORTAÇÃO}

Ao serem analisados os fatores externos que afetam a estimação de custos na importação, identificou-se que os fatores relacionados ao fornecedor são considerados muito importantes. A "confiabilidade no fornecedor" é um fator em destaque, pois caso a 
indústria não tenha total confiança a respeito do fornecedor proponente, este nem poderá ser credenciado; além das habilidades técnicas, a indústria observa a situação financeira do fornecedor para honrar os compromissos assumidos. A análise dos fornecedores envolve três parâmetros de avaliação:

1) Capacidade técnica para fazer, traduzido do termo inglês capability; 2) Capacidade produtiva que analisa o volume de produção; e 3) Capacidade financeira de permanecer em atividade.

O fator referente aos "negócios potenciais com o fornecedor" foi analisado com atenção intermediária, pois a indústria apresenta inclusive políticas comerciais que incentivam o desenvolvimento de fornecedores locais para algumas peças em específico; no entanto, pelo fato de ser a líder do canal de comercialização, o maior interesse por negócios em potencial se origina do fornecedor em relação à indústria. $O$ fator "comunicação/negociação com o fornecedor" foi considerado como muito importante, pois diante da agilidade na comercialização e das necessidades de comparações de preços com todos os fornecedores da indústria no mundo, o fornecedor precisa apresentar flexibilidade em determinadas negociações.

Ainda referente aos fatores externos, foram analisados os fatores relacionados ao mercado. O fator "conquista de novos clientes" foi analisado como pouco importante para a estimação de custos na importação, pois os clientes da indústria automobilística, que são as concessionárias e o usuário final dos carros, não exercem pressões extremas a ponto de decidirem comprar o carro por este ter um novo fornecedor ou tipo de produto, de forma geral. Considera-se, contudo, que em alguns casos é percebido, principalmente, em acessórios, a preferência dos usuários finais por determinada especificação, mas esta análise é realizada pelo setor de pesquisa e desenvolvimento. Portanto, após os testes do carro são analisados os fornecedores habilitados a fornecer as peças. A partir deste cenário, observa-se se as peças oferecidas apresentam as mesmas qualificações. Desta forma o fator "conquista de novos clientes" e "interesse de clientes da sua empresa" é observado como pouco importante no processo de estimação de custos para a importação. 
Os "benefícios governamentais" e as "restrições governamentais" são considerados pouco importante no processo de estimação de custos na importação. Referente aos benefícios, a indústria não interessa pelo financiamento do Brasil, por ter viabilidade financeira de suas ações e apoio do grupo mundial. As restrições governamentais, apontadas como fatores externos, referentes aos tributos também foram consideradas pouco importante para a importação. No entanto, percebe-se que este fator foi analisado com pequena pontuação, pelo setor já apresentar incentivos interessantes para o ramo automobilístico.Um fator externo apontado como muito importante foi o "preço da concorrência", ou seja, dos demais fornecedores. Por meio de um painel de controles, o comercializador internacional pode verificar o preço de todos os locais no mundo que fabricam a peça e estão credenciados à fábrica. Ele busca realizar a compra mais interessante para a indústria brasileira em termos financeiros, não deixando de observar contudo o desenvolvimento de novos fornecedores.

Referente aos fatores internos que afetam a estimação de custos na importação, identificou-se fatores relacionados à própria empresa e fatores relacionados ao produto importado e à sua necessidade. O fator "risco de perdas" foi apreciado como muito importante, a empresa esclarece que uma peça de análise referente a este fator é o vidro, pois no transporte pode ocorrer à quebra dos mesmos. Outro exemplo apresentado é o pára-choque, para que não ocorram perdas de peças o acondicionamento no contêiner precisa ser tão bem analisado que a segurança das peças inviabiliza os custos de transportes, pois o distanciamento entre as mesmas é elevado e neste caso a fábrica passaria a transportar cargas com espaços vazios.

A "capacidade de estocagem" do produto é um fator muito importante analisado na estimação de custos. Este fator é relaciona-se ao "tempo de entrega do produto" que também apresenta uma valência muito importante. A fábrica atua com o modelo just in time e portanto, procede a gestão do estoque circulante, ou seja, o estoque em trânsito. Portanto, o tempo de entrega e a pontualidade da mesma são de extrema importância. De forma geral, os produtos importados consistem em peças genéricas a serem 
utilizadas em larga escala, ou seja, em um grande número de carros. Para peças mais específicas, como por exemplo, o chicote do carro com ar-condicionado e rádio, a empresa desenvolve canais de comercialização que promovam o suprimento nacional e próximo à unidade fabril para minimizar a necessidade de estocagem, uma vez que a importação de um contêiner da peça específica requereria de um estoque na fábrica. Contudo, a fábrica apresenta um volume reduzido de algumas peças por questões de segurança. Considera-se ainda que algumas peças muito específicas e de avanço tecnológico mais recente ainda não apresentam fornecedores locais, como é o caso da direção elétrica de um carro mais recente no mercado brasileiro, para o fornecimento desta peça necessita-se portanto, da importação.

A "confiabilidade no produto importado" foi contemplada como fator interno à empresa, no entanto, a análise do mesmo aproximou-se da "confiabilidade do fornecedor" considerado como fator externo. Tal impacto procede pelo processo interno da empresa que exerce a certificação dos fornecedores internacionalmente. Portanto, o produto é padronizado e o fornecedor recebe a certificação para proceder a produção. Além desta análise considerou-se que alguns fornecedores apresentam iniciativas para aperfeiçoar o uso da peça ou desenvolver novos aplicativos para a mesma, nestes casos, quando o setor de pesquisa e desenvolvimento analisa a peça e procede a aprovação da melhoria incremental ou revolucionária, a fábrica compra a planta da peça do fornecedor e inicia o processo de certificação dos fornecedores. A este processo a empresa denomina de processo co-designer. Desta forma, a fábrica não apresenta dependência de apenas um fornecedor, mas possibilita a concorrência entre eles.

Por isto, o fator interno "possibilidade de avanços tecnológicos do produto" foi analisado como pouco importante. A Figura 1 apresenta os principais fatores analisados para a estimação de custos na atividade de importação. 


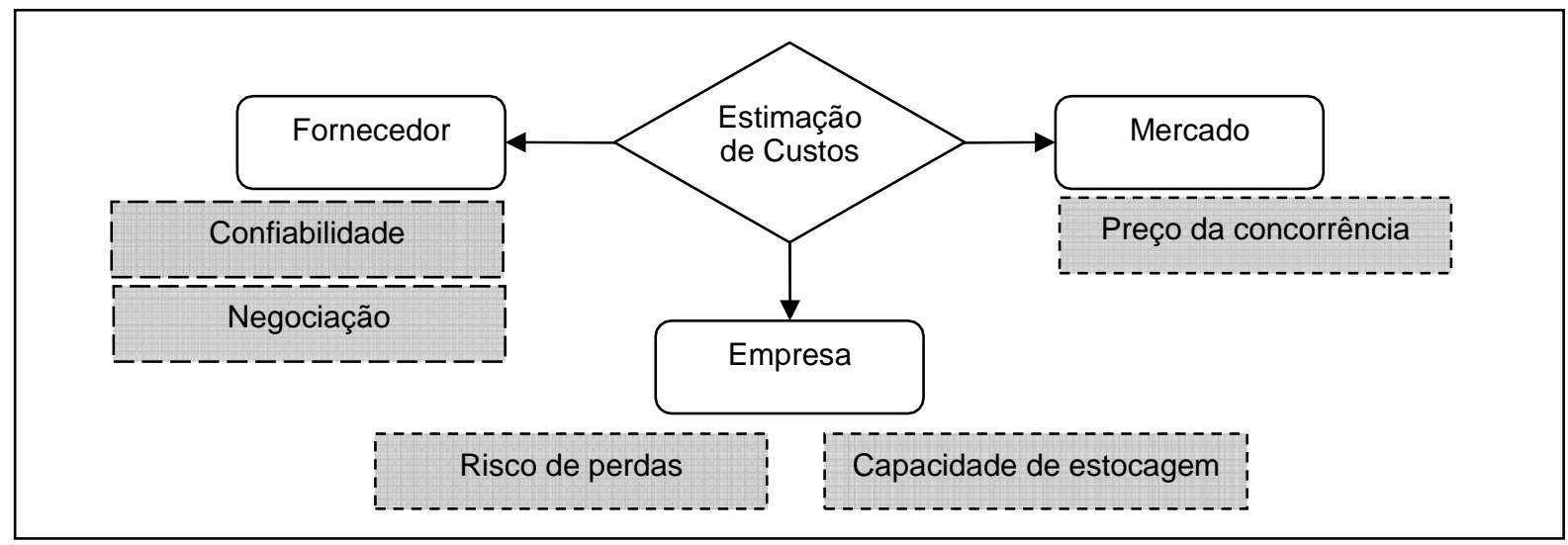

Figura 1: Principais fatores analisados na empresa automobilística

Os fatores que influenciam a importação foram analisados e interpretados a partir da investigação em um período de tempo reduzido. Para que estes fatores sejam refinados e identificados para a definição de um sistema de suporte à decisão mais específico, recomenda-se o acompanhamento das ações empresariais e o uso da técnica de prototipação. Ao desenvolver esta análise pode-se perceber que outros fatores podem ser identificados e definidos a partir do aprofundamento da pesquisa e da convivência constante no setor de compras com maior intensidade e frequência. Considera-se, contudo, que para o desenvolvimento deste tipo de pesquisa seria necessário obter da fábrica um apoio mais específico referente a acessibilidade às informações e disponibilidade de tempo dos funcionários atuantes no setor. De qualquer maneira, esta análise de fatores é um avanço para o estudo da estimação de custos de importação no setor automobilístico.

\section{SISTEMA DE ESTIMAÇÃO DE CUSTOS PARA IMPORTAÇÃO NA FÁBRICA}

A empresa realiza a estimativa de custos antes das importações com a utilização do sistema desenvolvido internamente, e a utilização de duas planilhas eletrônicas geradas no aplicado Excel, da Microsoft.

O sistema desenvolvido pela empresa oferece informações do custo por unidade 
das peças, identificadas por código. No sistema é apresentado o custo de cada peça por pólo de produção em todo o mundo. Estas informações são exportadas para uma planilha eletrônica e apresenta como informação final a classificação por fornecedor em Euro. A seguir é apresentada uma aproximação do modelo utilizado pela empresa para analisar os possíveis fornecedores cadastrados. A princípio é apresentado o valor por peça em cada moeda, em seguida é apresentado o percentual de fornecimento e o comparativo dos valores em Euro. Ao final é apresentada uma classificação por peça. A coluna de classificação é preenchida pelo comprador que determina pelo volume a ser comprado e pelo apresentado, qual o primeiro fornecedor a ser contactado.

\begin{tabular}{|c|c|c|c|c|c|c|c|c|c|}
\hline 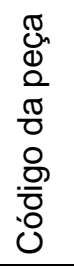 & 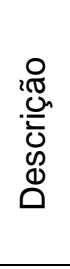 & 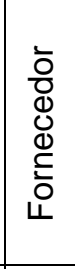 & 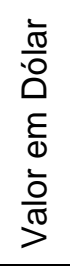 & 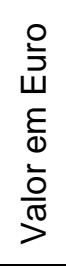 & 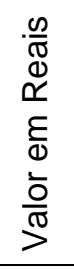 & 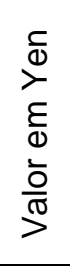 & 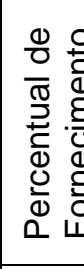 & 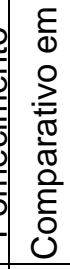 & 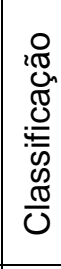 \\
\hline$x X$ & & Ar & 4.0 & & & & 20 & 3. & 2 \\
\hline$X X$ & & $\mathrm{Bra}$ & & & 9.0 & & 80 & 3. & 3 \\
\hline YY & & Ita. & & 3,0 & & & 100 & 3 & 1 \\
\hline
\end{tabular}

Quadro 2: Planilha de auxílio à análise de fornecedores

Depois de identificados os fornecedores do grupo, são estabelecidos contatos por e-mail para que preenchimento de uma outra planilha com os custos de transportes internos. Nesta outra análise são apresentadas as estimações de custos para a importação. O fornecedor, ao receber a intenção de compra da filial brasileira, preenche uma tabela que estima os custos logísticos.

Para a análise, o estimador de custos da filial brasileira considera o acréscimo do índice de nacionalização do produto, que considera uma estimativa de inflação e variação de câmbio. Atualmente, para este índice é utilizado o IGP DI - Índice Geral de Preços - Disponibilidade Interna. Apesar das compras entre as filiais não ter como fundamental ênfase o lucro, mas sim a utilização da capacidade produtiva de cada 
unidade, pelas leis governamentais a empresa necessita inserir à estimativa o Mark-up, que consiste em uma porcentagem aplicada ao custo base. Esse processo inclui o lucro desejado e quaisquer custos não incluídos no custo base, segundo Hansen e Mowen (2001). O valor do transporte, destacado no

Quadro 3, é apresentado por volume, ou seja, pela representação de metros cúbicos que cada peça representa no contêiner com a embalagem. O termo Ingombro, utilizado no Quadro 3, refere-se ao volume unitário da peça.

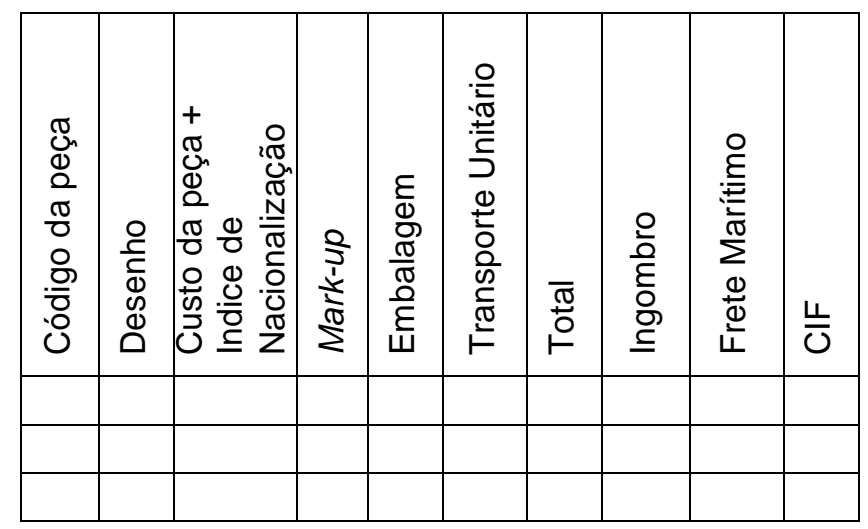

Quadro 3: Planilha de estimação de custos para a importação

A um entrevistado solicitou-se uma relação de itens que poderiam ser utilizados na planilha adotada pela empresa para a realização das projeções, ou seja, das estimativas. O entrevistado mencionou que as planilhas utilizam Incoterms, frete internacional e imposto de importação. No entanto, no dado documental coletado não foi verificada a incidência do imposto de importação na planilha de análise. Sobre os itens apresentados como não utilizados na planilha, percebeu-se que alguns incidem no processo, mas não são analisados no modelo atual utilizado pela empresa. Observouse, também, que outros itens foram apontados como desconhecidos pelo entrevistado.

A partir das análises desenvolvidas percebe-se que o sistema de análise da empresa apresenta limitação de variáveis para o analista de importação, o que permite maior agilidade no trabalho desenvolvido, mas influenciam as tomadas de decisão, por não serem analisadas todas as variáveis possíveis. Considera-se que esta é uma política organizacional traçada em virtude da estrutura organizacional da empresa. 
Contudo, há de se considerar a possibilidade de centralizar tais informações para que o analista de importação possa deter mais informações para auxiliar na tomada de decisões. Um outro fator considerado consistiu na análise pós-fato, pois o analista após proceder ao processo decisório não tem um retorno final sobre as estimativas projetadas de forma automática.

O analista de compras internacionais pondera que o processo no modelo atual é resultado de um trabalho de muitos anos. Há poucos anos o processo era muito complexo e requeria a transmissão de muitas informações que não auxiliavam no processo decisório; questionava-se inclusive a necessidade de coletar tantos dados. A partir das análises desenvolvidas na empresa, o processo passou a ser mais conciso, ou seja, objetivo; apresentando informações completas, exatas, confiáveis, úteis, relevantes, compreensíveis e consistentes.

A análise do sistema por um de seus usuários classificou que o uso das planilhas e do sistema é muito bom por poupar tempo, aumentar a produtividade, possibilitar executar mais trabalho do que seria possível sem ela, melhorar o trabalho do usuário e sua satisfação. No entanto, apesar do usuário responder que o sistema e as planilhas atendem às necessidades do usuário, ajudam no controle gerencial do processo de trabalho, melhoram o controle gerencial e ajudam no controle gerencial da performance; não foram identificados atributos que sustentem estas afirmações pela análise documental realizada.

\section{CONSIDERAÇÕES FINAIS}

Este artigo apresentou uma análise descritiva da atividade de importação e da estimação de custos da indústria automobilística. A partir da revisão da literatura e do desenvolvimento do estudo de caso foi possível elucidar como são tratados vários componentes de custos logísticos envolvidos no processo de importação, suas etapas e fatores. Com o desenvolvimento do estudo de caso foi possível identificar que a indústria, na maioria dos processos de importação, realiza o processo de compra a 
partir do estágio 3, do modelo apresentado por Kotabe e Helsen (2000). As fases de compra do departamento de importação contemplam os oito estágios apresentados por Kotler (2000), e a grande maioria dos produtos importados consiste em recompra simples.

Em relação aos componentes de custos, foi observado que os INCOTERMS mais utilizados são CIF e FOB. O pós-transporte é coordenado pelo departamento de logística da empresa. Sobre a embalagem, em virtude dos produtos serem volumosos e pesados, utiliza-se o fechamento de contêineres, com a embalagem unitária em madeira. No entanto, na maioria das vezes, ocorre o emprego da embalagem secundária, com a utilização de paletes. O despacho aduaneiro é feito por uma empresa que tem contrato fixo com a fábrica. Esta empresa atua como despachante e agente de cargas, além da existência de um operador logístico. O custo do pedido não é oneroso e apresenta simplificação na comunicação a partir de sua forma concisa e direta. Os pedidos do setor de importação não são automáticos. Em relação ao pedido observa-se que o sistema pode incorporar uma integração maior e, desta forma, seriam eliminadas as planilhas eletrônicas que representam uma grande circulação por e-mail. Sobre os tributos, constatou-se que a empresa não apresenta uma área de gerência de impostos integrada ao setor de importação.

O levantamento dos fatores permitiu identificar as análises realizadas pelo estimador de custos no momento que compreende a decisão de compra. $O$ fator confiabilidade no fornecedor recebeu uma importante atribuição, e a empresa analisa os fornecedores a partir de três parâmetros de avaliação que compreendem a capacidade técnica, a capacidade produtiva e a capacidade financeira. Um outro fator que recebeu destaque foi o preço da concorrência, pois o comercializador internacional verifica o preço de todos os locais do mundo por meio do sistema da empresa. Portanto, a competitividade entre os fornecedores credenciados é analisada constantemente.

Referente aos fatores internos, percebeu-se que estes são relacionados à própria empresa e ao produto importado. Em virtude do tipo de material transportado, 
identificou-se que o risco de perdas é muito importante e pode até inviabilizar a transação. Pela empresa atuar com o modelo just in time, o fator capacidade de estocagem é considerado como muito importante, pois a empresa conta inclusive com estoque em trânsito. A confiabilidade no produto importado foi apresentada como consequência da confiabilidade no fornecedor, pois para a empresa realizar a transação com o fornecedor são realizados testes por uma equipe que emite uma certificação sempre que a avaliação for positiva.

A partir da análise dos fatores externos e internos, pode-se perceber que os demais fatores podem ser identificados e definidos mediante o aprofundamento da pesquisa e da convivência constante no setor de compras com maior intensidade e frequência. Destaca-se que para a realização desta pesquisa contou-se com o interesse da empresa que permitiu o acesso às informações, além da disponibilidade de tempo dos funcionários atuantes no setor.

Amparados pela proposta de Alter (1996), que contempla a avaliação dos Sis pela Análise Centrada no Trabalho, foi analisada a empresa e identificadas as ações desenvolvidas pelo seu setor de compras internacionais. Percebeu-se que a análise custo/benefício proposta por Stair (1998) é utilizada pela empresa e que esta prima pela facilidade de uso e utilidade do sistema, conforme salientado por Freitas; Ballaz e Moscarola (1994). Contudo, a empresa não disponibiliza um aplicativo que permita analisar os fatores expostos anteriormente; portanto, os fatores são analisados sem um sistema de apoio à decisão. Esta atitude empresarial permite que a tomada de decisão seja procedida sem orientação específica ao funcionário, o que representa um risco, pois o indivíduo decide em função de sua percepção da situação apresentada de acordo com os eventos futuros, as consequências das alternativas e as regras ou princípios que estabelecem a ordem de preferência do indivíduo. Conforme afirmam March e Simon (1972, p. 212), os passos que conduzem o tomador de decisão a definir uma situação envolvem um complexo de processos afetivos e cognitivos, pois "o que uma pessoa deseja e aprecia, influencia o que ela vê, e o que ela vê influencia o que quer e aprecia". 
A partir deste estudo de caso, as empresas importadoras podem ter uma orientação em relação aos procedimentos necessários para a tomada de decisão. $O$ levantamento bibliográfico permitiu desenvolver um instrumento de coleta de dados que auxilia o leitor a elucidar o assunto. Com a realização da pesquisa foi possível identificar quais informações a empresa analisa para a tomada de decisões em relação à importação e contribuir para a compreensão da atividade de importação com a utilização de estimação de custos. Para futuros estudos pretende-se desenvolver uma pesquisa quantitativa que demonstre como ocorre a estimação de custos dos produtos importados pelas principais empresas importadoras do estado de Minas Gerais.

\section{REFERÊNCIAS}

ALMEIDA, S. O; PEREIRA; R. C. de F.; e LARÁN, J. A. A. (2002). Influência da Satisfação, da Confiança e do Comportamento em Trocas Relacionais com Objetivos de Longo Prazo: um estudo qualitativo no contexto bussiness-to bussiness. Porto Alegre: Anais...do CDROM da Assembléia do CLADEA.

ALTER, S. (1996). Information Systems - a management perspective. (2 ed.). EUA, Addison-Wesley Educational Publishers Inc, 587p.

BABBIE, E. (1999). Métodos de Pesquisa de Survey. Belo Horizonte, Ed. da UFMG, $519 p$.

BAILY, P; FARMER, D; JESSOP, D e JONES, D. (2000). Compras: princípios e administração. Tradução Ailton Bomfim Brandão. São Paulo, Atlas, 471p.

BALLOU, R. H. Gerenciamento da Cadeia de Suprimentos: planejamento, organização e logística empresarial. Tradução: Elias Pereira. (4 ed.). Porto Alegre, Bookman, 518 p.

BARDIN, L. (1977). Análise de conteúdo. São Paulo, Livraria Martins Fontes, 225p.

CARDOSO, D. (2001). Avaliação do SAP R/3 como instrumento para a gestão financeira: um estudo de caso no setor siderúrgico brasileiro. Belo Horizonte, UFMG, $227 \mathrm{p}$.

COHEN, M.F.; SOUZA, A. A. de. (2001). Avaliação de Sistemas de Informações: um estudo de caso na Suprama. In: ENANPAD, 25, Campinas. Anais...Campinas. CDROM. 
COOPER, D. R.; SCHINDLER, P. S. (2003). Métodos de Pesquisa em Administração. Tradução: Luciana de Oliveira da Rocha. (7 ed.). Porto Alegre, Bookman, 640p.

FREITAS, H.; BALLAZ, B. e MOSCAROLA, J. (1994). Avaliação de Sistemas de Informações. Rausp. São Paulo, 29(4):36-55.

GOBBO, M. A. T. (2002). Impacto da implantação de um novo sistema de informação em uma empresa do setor de energia elétrica. Porto Alegre, UFRGS, 114p.

HANSEN, D. R. e MOWEN, M. M. (2001). Gestão de custos: contabilidade e Controle. São Paulo, Pioneira Thomson Learning, 783 p.

KILPATRICK. (1988). Editorial. Journal for Research in Mathematic. Education.

KOTABE, M. e HELSEN, K. (2000). Administração de marketing global. Traduzido por Ailton Bonfim Brandão. São Paulo, Atlas, 709p.

KOTLER, P. (2000). Administração de Marketing: a edição do novo milênio. Tradução: Bazán Tecnologia e Lingüística. São Paulo, Prentice Hall, 736 p.

LOPEZ, J. M. C. (2000). Os Custos Logísticos do Comércio Exterior Brasileiro. São Paulo, Aduaneiras, $136 \mathrm{p}$.

MAÇADA, A. C. G.; et al. (2000). Medindo a satisfação dos usuários de um Sistema de Apoio à Decisão. In: ENANPAD, 24, Florianópolis. Anais...CD-ROM.

SOUZA, A. A. e KINGSMAN, B. (1999). CEPSS - A Rule Based Expert Decision Support Tool for the Cost Estimation and Pricing Decision Process. Rio de Janeiro: Anais do XIX Encontro Nacional de Engenharia de Produção e $V$ Congresso Internacional de Engenharia Industrial.

STAIR, R. M. (1998). Princípios de Sistemas de Informação - uma abordagem gerencial. (2 ed.). Rio de Janeiro, LTC. 451p.

TORKZADEH, G.; DOLL W. J. (1999). The development of a tool for a measuring the perceived impact of a information technology on work. Omega. The international journal of management Science, 27:327-339.

TRIVIÑOS, A.N.S. (1987). Introdução à Pesquisa em Ciências Sociais: a Pesquisa Qualitativa em Educação. São Paulo, Atlas, 175 p.

YIN, R.K. (2001). Estudo de caso: planejamento e métodos. (2 ed.). Tradução Daniel 
Grassi. Porto Alegre, Bookman, 205 p.

ZANOTELI, E. J. (2001). Sistemas de Informações Gerenciais: o uso da informação contábil como apoio à tomada de decisão. Belo Horizonte, UFMG, 258p.

ZWASS, V. (1992). Management Information Systems. EUA, WCB. 896p.

WILLIAMSON, O. E. (1985). The economic institution of capitalism. New York, The New York Free Press, 286p.

ROSS, S. A.; WESTERFIELD, R.W. e JAFFE, J. F. (1995). Administração financeira. São Paulo, Atlas, 698 p.

CARVALHO, L. F. N. (2002). O problema da confiança e seus impactos sobre os custos de transação. Porto Alegre. Anais do CD-ROM da Assembléia do CLADEA, 16p.

BARBOSA FILHO, C. A. e FREIRE, F. S. (1999). Algumas considerações sobre o Custo Brasil. Anais do VI Congresso Brasileiro de Custos.

SANTOS, A.C. (2002). Gestão de Organizações no Agronegócio. Lavras, MG. (Dissertação de Mestrado). Universidade Federal de Lavras, 77p.

Data de Submissão: 30/07/2007

Data de Aceite: 08/03/2008 